\title{
EXTRAÇÃO DE ÍNDIO A PARTIR DE TELAS DE LCD DE TELEFONES CELULARES ATRAVÉS DE LIXIVIAÇÃO
}

\author{
A. B. ARGENTA' ${ }^{1}$, C. M. dos REIS ${ }^{1}$, E. H. TANABE ${ }^{1}$, G. P. de MELLO $^{1}$ e D. A. \\ BERTUOL $^{1}$ \\ ${ }^{1}$ Universidade Federal de Santa Maria, Departamento de Engenharia Química \\ E-mail para contato: carolinereis08@gmail.com
}

\begin{abstract}
RESUMO - Desde a sua invenção, as telas de cristal líquido (LCD) se tornaram um dos principais tipos de displays em televisores, computadores e telefones celulares. Os telefones celulares se destacam pelo ciclo de vida curto e quantidade de materiais perigosos que possuem. Em sua composição há cerca de 40 elementos químicos, dos quais, 20 são metais. Dentre esses metais, está o Índio (In), um metal raro e muito versátil. Dessa forma, este trabalho teve como objetivo a extração do In das telas de LCD, utilizando ácidos orgânicos (ácido málico e ácido cítrico) como forma de substituição de ácidos com efeitos nocivos ao meio ambiente. O estudo compreendeu a separação das telas de LCD dos celulares, sua moagem em moinho de bolas com posterior análise granulométrica, lixiviação e análise por espectrofotometria de absorção atômica de chama (AAS). $\mathrm{Na}$ melhor condição obtida, recuperou-se $70,52 \%$ do Índio presente nas telas de LCDs, com Ácido cítrico, numa temperatura de $90^{\circ} \mathrm{C}$ e por duas horas.
\end{abstract}

\section{INTRODUÇÃO}

O setor de equipamentos elétricos e eletrônicos (EEE) é um dos que mais cresce no mundo. Este crescimento tão rápido das inovações faz com que os EEE se tornem obsoletos em pouco tempo. Os principais REEE são produtos como TVs, computadores, telefones celulares e eletrodomésticos, os quais são considerados lixo eletrônico ao se tornarem obsoletos ou deixarem de funcionar (STIANNOPKAO, S.; WONG, M., 2013).

Como consequência do crescimento das inovações, a geração de resíduos vem crescendo de maneira alarmante e gerando materiais que contem substâncias prejudiciais ao ser humano, e apresentam também materiais nobres e raros.

Os telefones celulares ganham destaque entre os REEE. A introdução de novas tecnologias em telefones celulares, mostra que esses aparelhos são, cada vez mais, vistos pelos usuários como obsoletos em pouco tempo. Telefones celulares são constituídos basicamente por teclado, bateria, display de cristal líquido (LCD), placa de circuito impresso, e outros acessórios. Nas telas de LCD, por exemplo, há multicamadas de materiais, entre as quais uma mistura de óxido de estanho e índio (ITO), composta de $80-90 \%$ de óxido de índio $\left(\mathrm{In}_{2} \mathrm{O}_{3}\right)$ e $10-20 \%$ de óxido de estanho $\left(\mathrm{SnO}_{2}\right)$, que reveste uma das camadas de vidro. 
O índio é um metal raro e valioso com recursos limitados, sua extração se dá principalmente como subproduto de minérios de zinco, variando de 1 a $100 \mathrm{~g} / \mathrm{t}$, valor menor do que seu conteúdo em telas LCDs. Sendo assim, as telas LCDs obsoletas que são consideradas como resíduos podem passar a ser um valioso recurso para a extração do metal Índio (DODBIBA, G. et al., 2012; VIROLAINEN, S.; IBANA, D.; PAATERO, E., 2011).

Os experimentos realizados no presente estudo tiveram como objetivo desenvolver um método eficaz de extração de Índio de telas LCD de telefones celulares, além de estudar os melhores parâmetros do processo.

\section{MATERIAIS E MÉTODOS}

\subsection{Desmantelamento dos Aparelhos}

Após a coleta dos celulares, por desmontagem manual, as telas de LCD foram separadas das outras partes de um celular, como carcaça polimérica, placa de circuito impressa, teclado, bateria, estrutura plástica, adesivos e alguns polímeros presentes na mesma. Porém, outros polímeros fazem parte da composição da tela. Estes estão aderidos fortemente à tela, necessitando, assim, do uso de reagentes químicos para auxiliar na remoção destes materiais.

Após o desmantelamento dos aparelhos, as telas de LCD foram submetidas à aplicação de acetona por $24 \mathrm{~h}$, a temperatura ambiente, para retirada dos polímeros fortemente aderidos à tela. A proporção de telas utilizadas para o volume de acetona foi de 1:10. Estas condições de razão Sólido-Líquido, tempo de aplicação, bem como o tipo de solvente utilizado, foram determinadas como sendo as melhores para remoção dos polímeros em estudos anteriores.

\subsection{Cominuição e análise granulométrica}

As telas de LCD foram moídas em moinho de bolas (marca Marconi). O processo de cominuição foi realizado durante o período de $4 \mathrm{~h}$ a uma frequência de $60 \mathrm{~Hz}$. Estes parâmetros foram os que proporcionaram melhor extração do metal desejado.

Após a etapa de cominuição, o material moído passou pela etapa de análise granulométrica em um conjunto de peneiras vibratórias de diversas aberturas de malha, da série Tyler. Após análise granulométrica, as partículas com diâmetro igual ou menor a $150 \mu \mathrm{m}$ foram misturadas e submetidas aos demais procedimentos realizados neste estudo.

\subsection{Lixiviação}

Após a classificação das partículas de telas LCDs, o pó de ITO foi submetido às lixiviações ácidas à pressão atmosférica com diferentes concentrações dos ácidos málico e cítrico a diferentes temperaturas e proporção soluto/solvente, para a escolha da melhor condição para a extração do índio da tela de LCD. Os parâmetros estudados foram: tempo, razão sólido- líquido, temperatura, concentração de ácido e volume de peróxido. 
Em estudo anterior, extraiu-se o valor máximo de $636 \mathrm{mg} / \mathrm{Kg}$ de In com água régia. Este resultado vai ser utilizado como padrão de extração para avaliarmos a quantidade de índio extraída das telas de LCD, devido a grande variação de quantidade de um autor para outro. Wang (2008) considera que a quantidade de In em telas LCD descartadas é de 102 $\mathrm{mg} / \mathrm{Kg}$ de telas, enquanto que Kunihiko (2009) considera que a quantidade de In, em telas LCD de telefones celulares, é de $1400 \mathrm{mg} / \mathrm{Kg}$ de telas.

O sistema utilizado para os experimentos de lixiviação foi composto por uma placa de aquecimento com agitador magnético $(600 \mathrm{rpm})$ e um frasco com três aberturas. Uma abertura permaneceu fechada durante os experimentos, em outra abertura foi inserido um termômetro e na terceira abertura foi conectado o sistema arrefecimento, composto por condensador e banho ultratermostático com circulação para evitar as perdas por evaporação. Primeiramente, estudou-se a melhor temperatura do processo, fixando-se as outras variáveis: tempo de reação de 1 hora; volume de peróxido de 5\%, razão sólido-líquido de $1 / 20$ e concentração do ácido de 1 molar. Após a definição de melhor temperatura, estudou-se a melhor concentração de ácido, fixando-se as outras variáveis e utilizando a temperatura definida anteriormente. Com a temperatura e a concentração de ácido definidas, seguiu-se os demais testes onde foi avaliada a melhor relação sólido-líquido. Posteriormente, foi estudado o volume de peróxido de hidrogênio adicionado ao sistema que proporcionou maior extração de In. O peróxido de hidrogênio é comumente utilizado como oxidante forte em combinação com ácidos para melhorar o desempenho na extração de metais. Sua concentração e a temperatura de processo são considerados os fatores que mais influenciam a extração de metais a partir de REEE.

Com as demais variáveis de processo definidas (temperatura, concentração de ácido, proporção sólido-líquido e volume de peróxido), realizou-se investigação do melhor tempo do processo de lixiviação. Para isso, todas as demais variáveis foram fixadas nas melhores condições já estabelecidas e variou-se o tempo de processo.

\subsection{Métodos Analíticos}

A solução ácida filtrada e diluída foi então analisada por espectrofotometria de absorção atômica de chama (AAS) série 240FS AA, da marca Agilent. Para confirmação da extração de In, o pó foi analisado em um espectrômetro de fluorescência de raio-X (XRF - Xray Fluorescence) modelo EDX-720, da marca Shimadzu.

\section{RESULTADOS}

\subsection{Lixiviação}

O primeiro parâmetro estudado foi a temperatura de operação. Os valores de concentração de In analisados por AAS, expressos em mg de In por kg de telas de LCD, obtidos para os experimentos a $30,50,70$ e $90{ }^{\circ} \mathrm{C}$ podem ser conferidos na Figura 1.

Figura 1: Efeito da temperatura no processo de lixiviação do pó de ITO. 

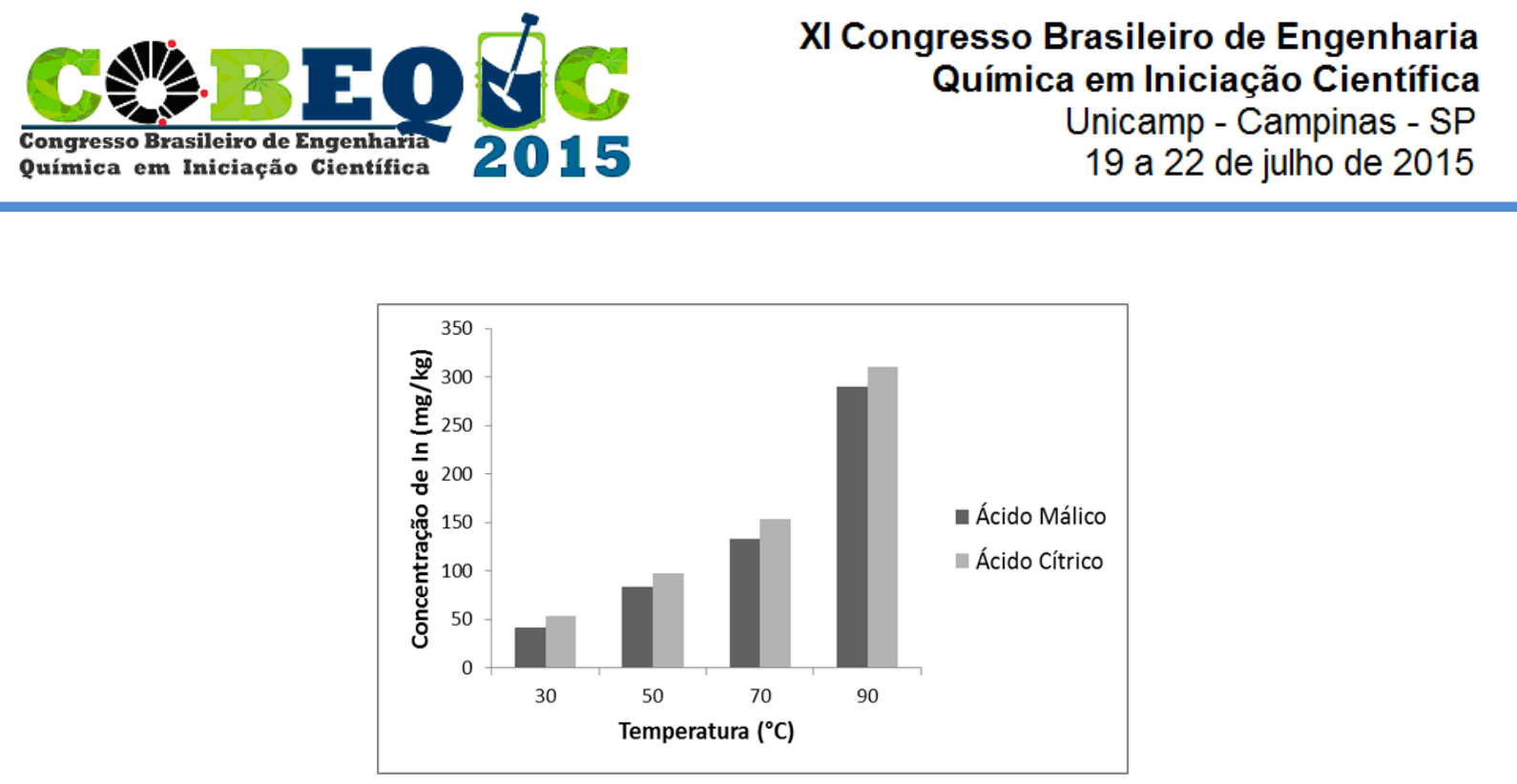

Ao visualizar a Figura 1, nota-se que com o aumento da temperatura, a lixiviação é favorecida e que dentre as temperaturas estudadas, a que proporcionou melhores resultados foi a lixiviação realizada a $90{ }^{\circ} \mathrm{C}$. Com a determinação de melhor temperatura, procederam-se os experimentos para determinação da melhor concentração de ácido utilizada para o processo de lixiviação. Os resultados destes experimentos são mostrados pela Figura 2.

Figura 2: Efeito da concentração de ácido no processo de lixiviação do pó de ITO.

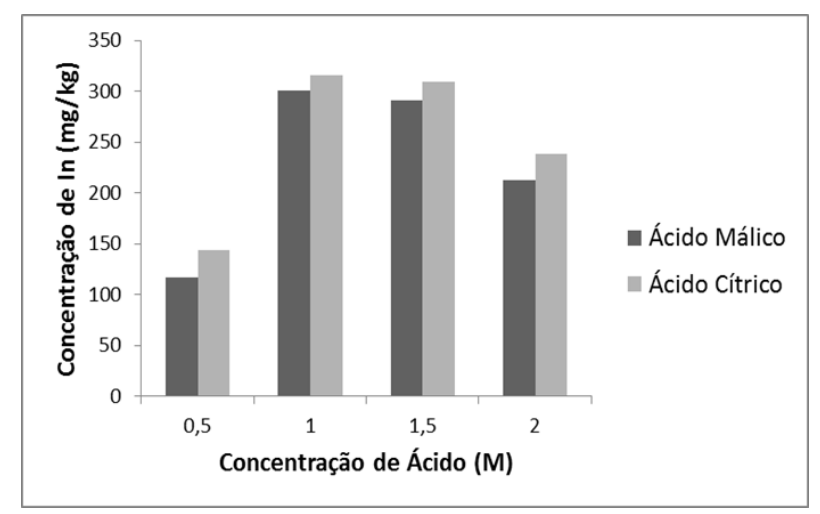

A partir dos dados mostrados pela Figura 2, pode-se verificar que a melhor concentração de ácido, tanto para os ácidos málico e ácido cítrico, foi a condição de $1 \mathrm{M}$. Esta concentração demonstrou extração de In na concentração de 300,9 e 315,5 mg/kg, para ácido málico e cítrico, respectivamente. Com a temperatura de processo e a melhor concentração dos ácidos definidos, realizaram-se os testes para determinação da melhor razão sólidolíquido, sendo os resultados mostrados na Figura 3.

Figura 3: Efeito da razão sólido-líquido no processo de lixiviação do pó de ITO. 

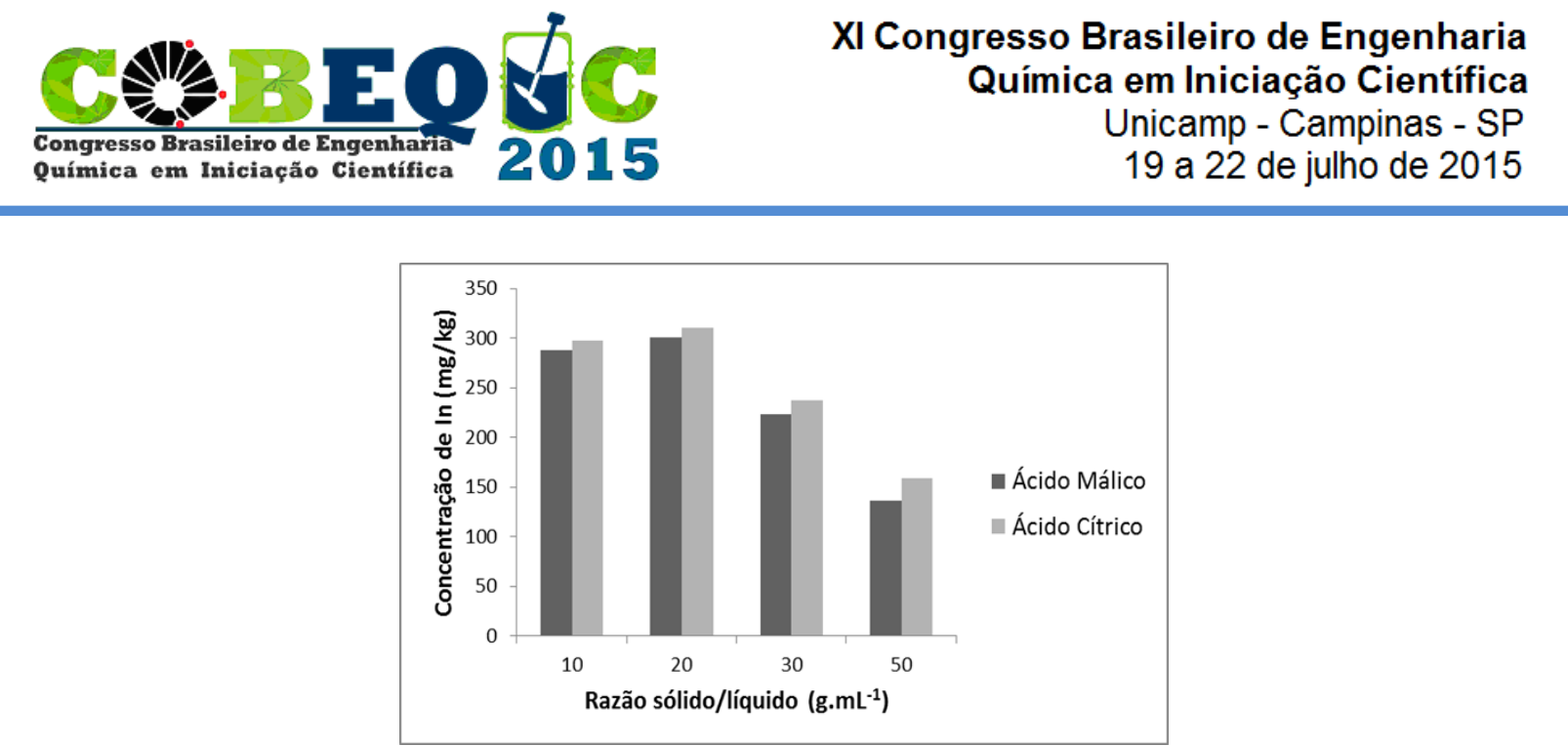

A Figura 3 mostra que a razão 1:20 foi a que obteve maior concentração de In, 301,2 e $310,5 \mathrm{mg} / \mathrm{kg}$ para os ácidos málico e cítrico, respectivamente. Como para a indústria, a economia de reagentes possui grande importância, o melhor valor alcançado, no teste de razão $1: 20$, se torna ainda mais satisfatório, já que não foi necessário o uso excessivo dos solventes para obtenção deste resultado.

No estudo do volume de peróxido, foram obtidos os resultados da Figura 4.

Figura 4: Efeito do volume de $\mathrm{H}_{2} \mathrm{O}_{2}$ no processo de lixiviação do pó de ITO.

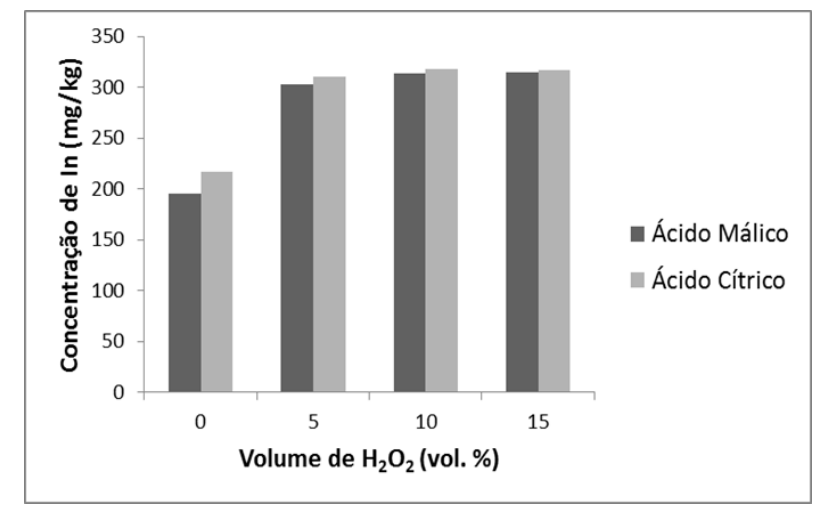

O volume de peróxido de hidrogênio empregado no processo, que resultou em concentração de In mais elevada foi de $10 \%$. Os testes realizados na ausência de $\mathrm{H}_{2} \mathrm{O}_{2}$ não resultaram em valores de concentração de In satisfatórios, indicando que a presença do mesmo se faz importante para o processo de lixiviação do metal.

Finalmente foram conduzidos experimentos para determinação do melhor tempo de processo de lixiviação. O estudo do tempo de operação que resulta em maior concentração do metal foi conduzido nas condições determinadas anteriormente e fixadas a $90{ }^{\circ} \mathrm{C}$, concentração de $1 \mathrm{M}$ de ácido, razão $1 / 20$ e volume de $\mathrm{H}_{2} \mathrm{O}_{2}$ de $10 \%$, resultando nos dados que podem ser observados na Figura 5.

Figura 5: Efeito do tempo no processo de lixiviação do pó de ITO. 

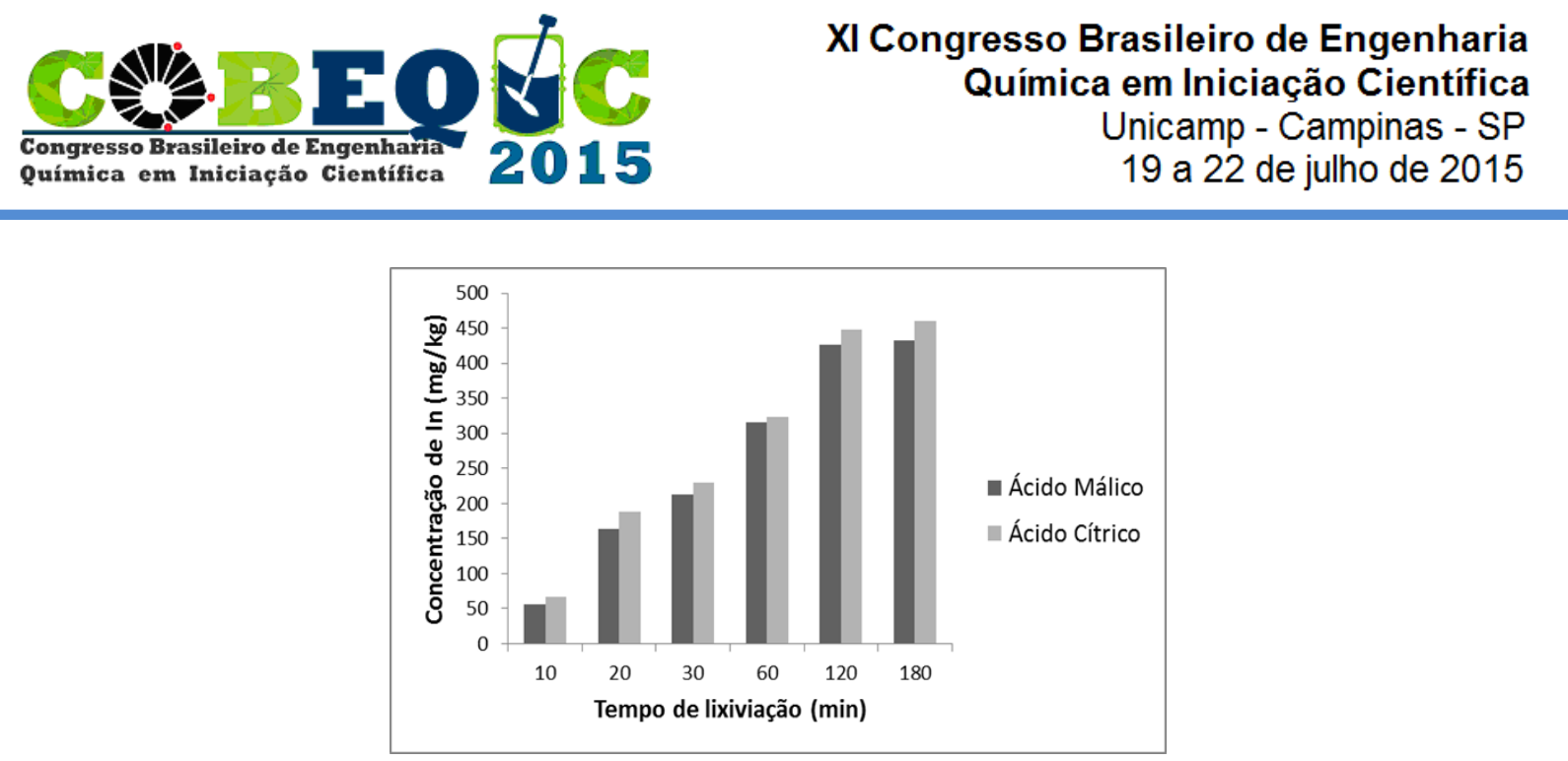

Como pode ser analisado na figura acima, os resultados melhores foram obtidos quando o tempo de lixiviação foi de 2 e $3 \mathrm{~h}$. No entanto, como industrialmente tempos longos de processo geram maiores custos, os experimentos com duração de $2 \mathrm{~h}$ se tornam mais vantajosos, já que é necessário mais $1 \mathrm{~h}$ de processo para obtenção de pequeno aumento na concentração.

\section{CONCLUSÃO}

A partir da análise das lixiviações à pressão atmosférica por AAS, verificou-se que os melhores parâmetros de extração, tanto para o Ácido cítrico quanto para o Ácido málico foram: tempo de $2 \mathrm{~h}$, temperatura de $90^{\circ} \mathrm{C}$, volume de peróxido de $10 \%$, relação sólido-líquido de 1:20 e concentração de ácido de 1M. Extraiu-se 67,08\% de In com Ácido Málico e 70,52\% com Ácido Cítrico. Logo, o ácido cítrico foi considerado o melhor solvente e será utilizado em situações posteriores na lixiviação à alta pressão para a otimização do tempo de extração.

Quando comparada com ácidos inorgânicos, a utilização de ácidos orgânicos na extração de metais é vantajosa, uma vez que estes são mais facilmente tratáveis. Ácido cítrico degrada facilmente sobre condições aeróbicas e anaeróbicas, logo, as soluções residuais podem ser tratadas facilmente e o ácido cítrico reusado em lixiviações subsequentes.

\section{REFERÊNCIAS}

1. DODBIBA, G. et al. Leaching of indium from obsolete liquid crystal displays: Comparing grinding with electrical disintegration in context of LCA. Waste Management, p. 1937-1944, 2012.

2. KUNIHIKO, T. et al: Recovering indium from the liquid crystal display of discarded cellular phones by means of chloride-induced vaporization at relatively low temperature. Metallurgical and materials transactions, p 891-899, 2009.

3. STIANNOPKAO, S.; WONG, M. H. Handling e-waste in developed and developing countries: Initiatives, practices, and consequences. Science of the Total Environment, p. 1147$1153,2013$.

4. VIROLAINEN, S.; IBANA, D.; PAATERO, E. Recovery of indium from indium tin oxide by solvent extraction. Hydrometallurgy, p. 56-61, 2011.

5. WANG H., Y. A study of the effects of LCD glass sand on the properties of concrete. Waste Management, p. 335-341, 2008. 